\title{
Early Pilomatrix Carcinoma: A Case Report With Emphasis on Molecular Pathology and Review of the Literature
}

\author{
Zaid Saeed Kamil, MD; Muskaan Sachdeva, BHSc; Jessica Kwapis, MD; Danny Ghazarian, MD
}

PRACTICE POINTS

- Clinicians and pathologists should be aware of pilomatrix carcinoma to facilitate early detection.

- Early diagnosis and prompt treatment of pilomatrix carcinoma is crucial in lowering recurrence rate and avoiding a poor outcome.

- Caudal-related homeobox transcription factor 2 and $\beta$-catenin components of the Wnt signaling pathway play an important role in the pathogenesis of pilomatrix carcinoma.

- Although controversial, wide local excision is the treatment of choice for pilomatrix carcinoma.

Pilomatrix carcinoma is a rare adnexal tumor with origin from the germinative matrical cells of the hair follicle. Clinically, it presents as a solitary lesion commonly found in the head and neck region and upper back. The tumors cannot be distinguished by their clinical appearance only and frequently are mistaken for cysts. Histopathologic examination provides the definitive diagnosis in most cases. Such carcinomas are aggressive neoplasms with a high probability of local recurrence and distant metastasis. Assessment of the Wnt signaling pathway components such as $\beta$-catenin, lymphoid enhancerbinding factor 1 (LEF-1) and caudal-related homeobox transcription factor 2 (CDX-2) potentially can be used for diagnostic purposes and targeted therapy. Herein, we report a rare and unique case of early pilomatrix carcinoma with intralesional melanocytes. We also review the molecular pathology and pathogenesis of these carcinomas as well as the significance of early diagnosis in their management.

Cutis. 2021;108:E24-E28.

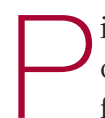

ilomatrix carcinoma is a rare adnexal tumor with origin from the germinative matrical cells of the hair follicle. Clinically, it presents as a solitary lesion commonly found in the head and neck region as well as the upper back. The tumors cannot be distinguished by their clinical appearance only and frequently are mistaken for cysts. Histopathologic examination provides the definitive diagnosis in most cases. These carcinomas are aggressive neoplasms with a high probability of local recurrence and distant metastasis. Assessment of the Wnt signaling pathway components such as $\beta$-catenin, lymphoid enhancerbinding factor 1 (LEF-1), and caudal-related homeobox transcription factor 2 (CDX-2) potentially can be used for diagnostic purposes and targeted therapy.

We report a rare and unique case of early pilomatrix carcinoma with intralesional melanocytes. We review the molecular pathology and pathogenesis of these carcinomas as well as the significance of early diagnosis.

\section{Case Report}

A 73-year-old man with a history of extensive sun exposure presented with a $1-\mathrm{cm}$, raised, rapidly growing,

Drs. Kamil and Ghazarian and Mr. Sachdeva are from the University of Toronto, Ontario, Canada. Drs. Kamil and Ghazarian are from the Department of Laboratory Medicine and Pathobiology. Drs. Kamil and Ghazarian also are from the Department of Laboratory Medicine and Pathobiology, University Health Network, Toronto. Dr. Kwapis is from Sensenbrenner Hospital, Kapuskasing, Ontario, and McMaster University, Hamilton, Ontario. The authors report no conflict of interest.

Correspondence: Zaid Saeed Kamil, MD, 200 Elizabeth St, Toronto, ON M5G 2C4, Canada (zaid.saeedkami@uhn.ca). doi:10.12788/cutis.0393 
slightly irregular, purple lesion on the right forearm of 3 months' duration with tendency to bleed. He did not have a history of skin cancers and was otherwise healthy. Excision was recommended due to the progressive and rapid growth of the lesion.

Histopathologic Findings-Gross examination revealed a $0.9 \times 0.7-\mathrm{cm}$, raised, slightly irregular lesion located $1 \mathrm{~mm}$ away from the closest peripheral margin. Histologically, the lesion was a relatively circumscribed, dermal-based basaloid neoplasm with slightly illdefined edges involving the superficial and deep dermis (Figure 1A). The neoplasm was formed predominantly of sheets of basaloid cells and small nests of ghost cells, in addition to some squamoid and transitional cells (Figure 1B). The basaloid cells exhibited severe nuclear atypia, pleomorphism, increased nuclear to cytoplasmic ratio (Figure 1C), minimal to moderate amounts of eosinophilic cytoplasm, enlarged nuclei, prominent nucleoli, and coarse chromatin pattern. Abundant mitotic activity and apoptotic bodies were present as well as focal area of central necrosis (Figure 1C). Also, melanophages and a multinucleated giant cell reaction was noted. Elastic trichrome special stain highlighted focal infiltration of the neoplastic cells into the adjacent desmoplastic stroma. Melanin stain was negative for melanin pigment within the neoplasm. Given the presence of severely atypical basaloid cells along with ghost cells indicating matrical differentiation, a diagnosis of pilomatrix carcinoma was rendered.

Immunohistochemistry-The neoplastic cells were diffusely positive for p63, CDX-2 (Figure 2A), $\beta$-catenin (Figure 2B), and CD10 (Figure 2C), and focally and weakly positive for cytokeratin (CK) 5, BerEP4 (staining the tumor periphery), androgen receptor, and CK18 (a lowmolecular-weight keratin). They were negative for monoclonal carcinoembryonic antigen, epithelial membrane antigen, CK7, CK20, CD34, SOX-10, CD56, synaptophysin, and chromogranin. Cytokeratin 14 was positive in the squamoid cells but negative in the basaloid cells. SOX-10 and melanoma cocktail immunostains demonstrated few intralesional dendritic melanocytes.

\section{Comment}

Pilomatrix carcinoma is a rare malignant cutaneous adnexal neoplasm with origin from the germinative matrix of the hair bulb region of hair follicles. Pilomatrix carcinoma was first reported in $19800^{1,2}$ These tumors are characterized by rapid growth and aggressive behavior. Their benign counterpart, pilomatrixoma, is a slowgrowing, dermal or subcutaneous tumor that rarely recurs after complete excision.

As with pilomatrixoma, pilomatrix carcinomas are asymptomatic and present as solitary dermal or subcutaneous masses ${ }^{3,4}$ that most commonly are found in the posterior neck, upper back, and preauricular regions of middle-aged or elderly adults with male predominance. ${ }^{5}$ They range in size from 0.5 to $20 \mathrm{~cm}$ with a mean of
$4 \mathrm{~cm}$ that is slightly larger than pilomatrixoma. Pilomatrix carcinomas predominantly are firm tumors with or without cystic components, and they exhibit a high probability of recurrence and have risk for distant metastasis. ${ }^{6-15}$

The differential diagnosis includes epidermal cysts, pilomatrixoma, basal cell carcinoma with matrical differentiation, trichoblastoma/trichoblastic carcinoma, and trichilemmal carcinoma. Pilomatrix carcinomas frequently are mistaken for epidermal cysts on clinical examination. Such a distinction can be easily resolved by histopathologic evaluation. The more challenging differential
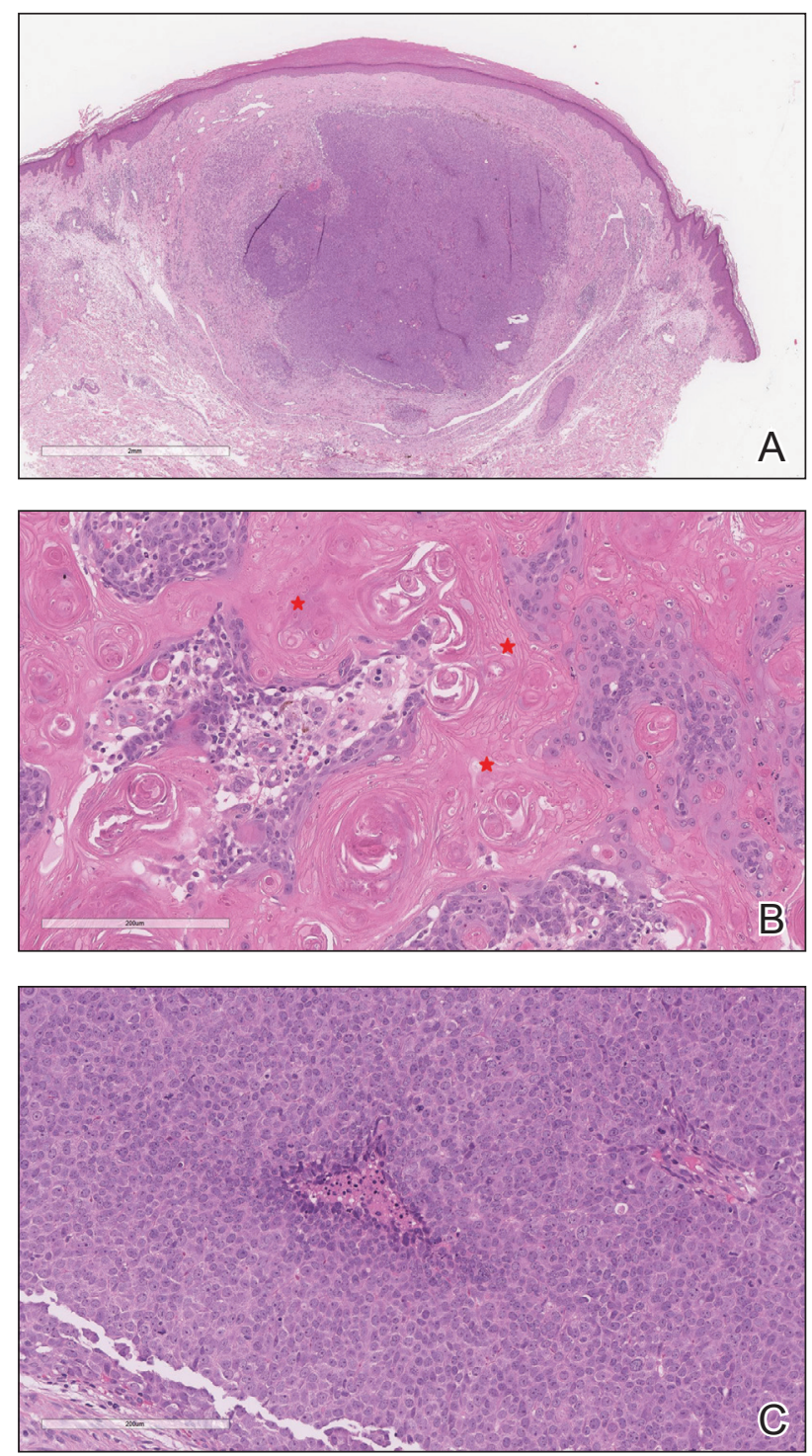

FIGURE 1. A, Histopathology of a pilomatrix carcinoma revealed a dermal-based neoplasm with irregular borders formed predominantly of basaloid cells $(H \& E$, original magnification $\times 20)$ (reference bar, $2 \mathrm{~mm}$ ). B, The neoplasm was formed of basaloid shadow cells (red stars) and squamoid cells (H\&E, original magnification $\times 200$ ) (reference bar, $200 \mu \mathrm{m}$ ). C, Marked cytologic atypia of basaloid cells with increased mitoses and focal necrosis also were present (H\&E, original magnification $\times 200$ ) (reference bar, $200 \mu \mathrm{m})$. 

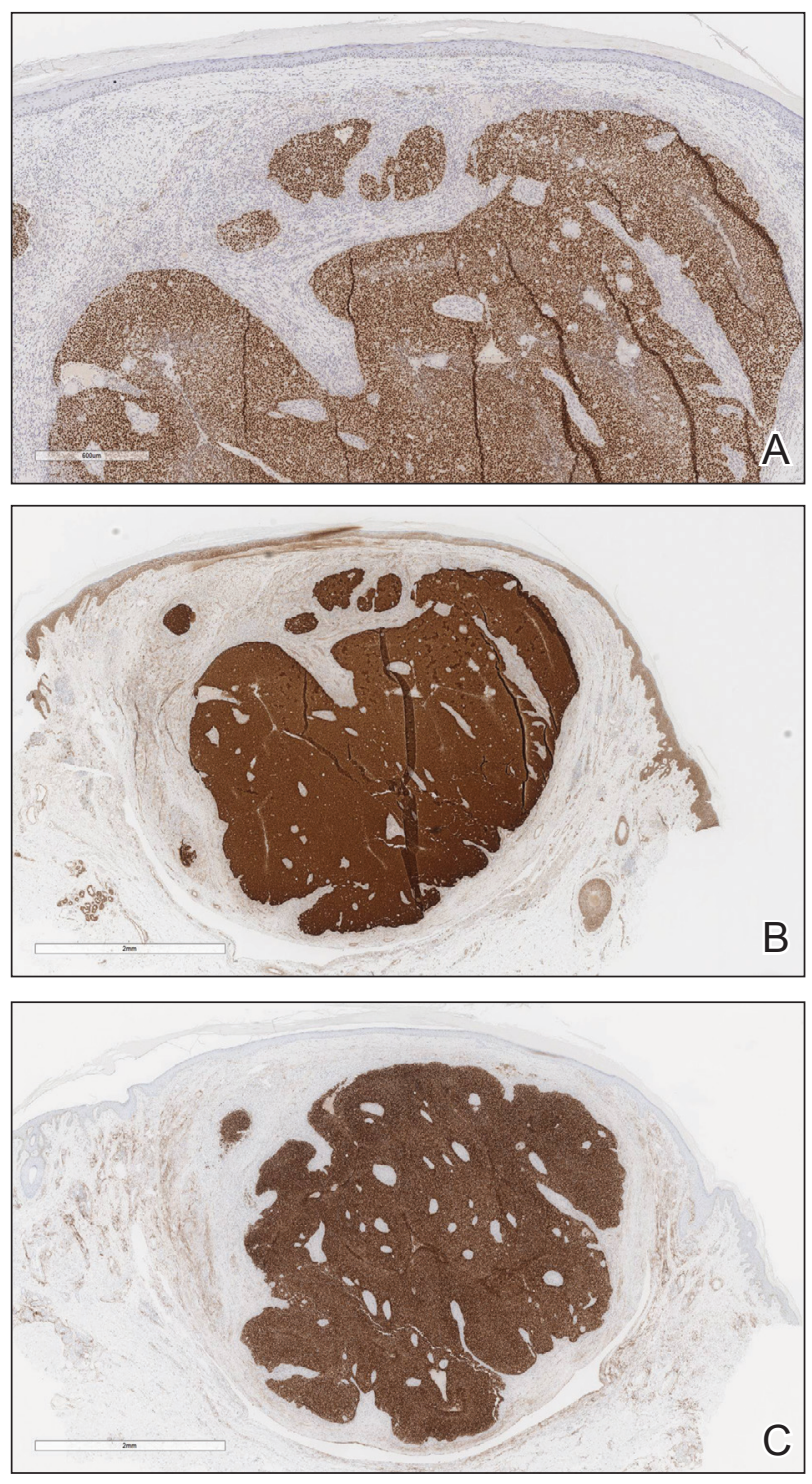

FIGURE 2. A-C, Immunohistochemistry revealed the tumor cells were positive for caudal-related homeobox transcription factor $2, \beta$-catenin, and CD10 (original magnifications $\times 40, \times 20$, and $\times 20$, respectively) (reference bars: $600 \mu \mathrm{m}, 2 \mathrm{~mm}$, and $2 \mathrm{~mm}$, respectively).

diagnosis is with pilomatrixoma. Histologically, pilomatrixomas consist of a distinct population of cells including basaloid, squamoid, transitional, and shadow cells in variable proportions. The basaloid cells transition to shadow cells in an organized zonal fashion. ${ }^{16}$ Compared to pilomatrixomas, pilomatrix carcinomas often show predominance of the basaloid cells; marked cytologic atypia and pleomorphism; numerous mitotic figures; deep infiltrative pattern into subcutaneous fat, fascia, and skeletal muscle; stromal desmoplasia; necrosis; and neurovascular invasion (Tables 1 and 2). Furthermore, the shadow cells tend to form a small nested pattern in pilomatrix carcinoma instead of the flat sheetlike pattern usually observed in pilomatrixoma. ${ }^{16}$ Basal cell carcinoma with matrical differentiation can pose a diagnostic challenge in the differential diagnosis; basal cell carcinoma usually exhibits a peripheral palisade of the basaloid cells accompanied by retraction spaces separating the tumor from the stroma. Trichoblastoma/ trichoblastic carcinoma with matrical differentiation can be distinguished by its exuberant stroma, prominent primitive hair follicles, and papillary mesenchymal bodies. Trichilemmal carcinomas are recognized by their connection to the overlying epidermis, peripheral palisading, and presence of clear cells, while pilomatrix carcinoma lacks connection to the surface epithelium.

Immunohistochemical stains have little to no role in the differential diagnosis, and morphology is the mainstay in making the diagnosis. Rarely, pilomatrix carcinoma can be confused with poorly differentiated sebaceous carcinoma and poorly differentiated squamous cell carcinoma. Although careful scrutiny of the histologic features may help identify mature sebocytes in sebaceous carcinoma, evidence of keratinization in squamous cell carcinoma and ghost cells in pilomatrix carcinoma, using a panel of immunohistochemical stains can be helpful in reaching the final diagnosis (Table 3 ).

The development of hair matrix tumors have been known to harbor mutations in exon 3 of the catenin beta-1 gene, CTNNB1, that encodes for $\beta$-catenin, a downstream effector in the Wnt signaling pathway responsible for differentiation, proliferation, and adhesion of epithelial stem cells. ${ }^{17-21}$ In a study conducted by Kazakov et al, ${ }^{22}$ DNA was extracted from 86 lesions: 4 were pilomatrixomas and 1 was a pilomatrix carcinoma. A polymerase chain reaction assay revealed 8 pathogenic variants of the $\beta$-catenin gene. D32Y (CTNNB1):c.94G >T (p.Asp32Tyr) and G34R (CTNNB1):c.100G>C (p.Gly34Arg) were the mutations present in pilomatrixoma and pilomatrix carcinoma, respectively. ${ }^{22}$ In addition, there are several proteins that are part of the Wnt pathway in addition to $\beta$-catenin-LEF-1 and CDX-2.

Tumminello and Hosler ${ }^{23}$ found that pilomatrixomas and pilomatrix carcinomas were positive for CDX-2, $\beta$-catenin, and LEF-1 by immunohistochemistry. These downstream molecules in the Wnt signaling pathway could have the potential to be used as diagnostic and prognostic markers. $2,13,15,23$

Although the pathogenesis is unclear, there are 2 possible mechanisms by which pilomatrix carcinomas develop. They can either arise as de novo tumors, or it is possible that initial mutations in $\beta$-catenin result in the formation of pilomatrixomas at an early age that may undergo malignant transformation in elderly patients over time with additional mutations. ${ }^{2}$

Our case was strongly and diffusely positive for $\beta$-catenin in a nuclear and cytoplasmic pattern and CDX-2 in a nuclear pattern, supporting the role of the Wnt signaling pathway in such tumors. Furthermore, our case demonstrated the presence of few intralesional normal dendritic melanocytes, a rare finding ${ }^{1,24,25}$ but not 
TABLE 1. Suggested Approach to the Diagnosis of Pilomatrix Carcinoma

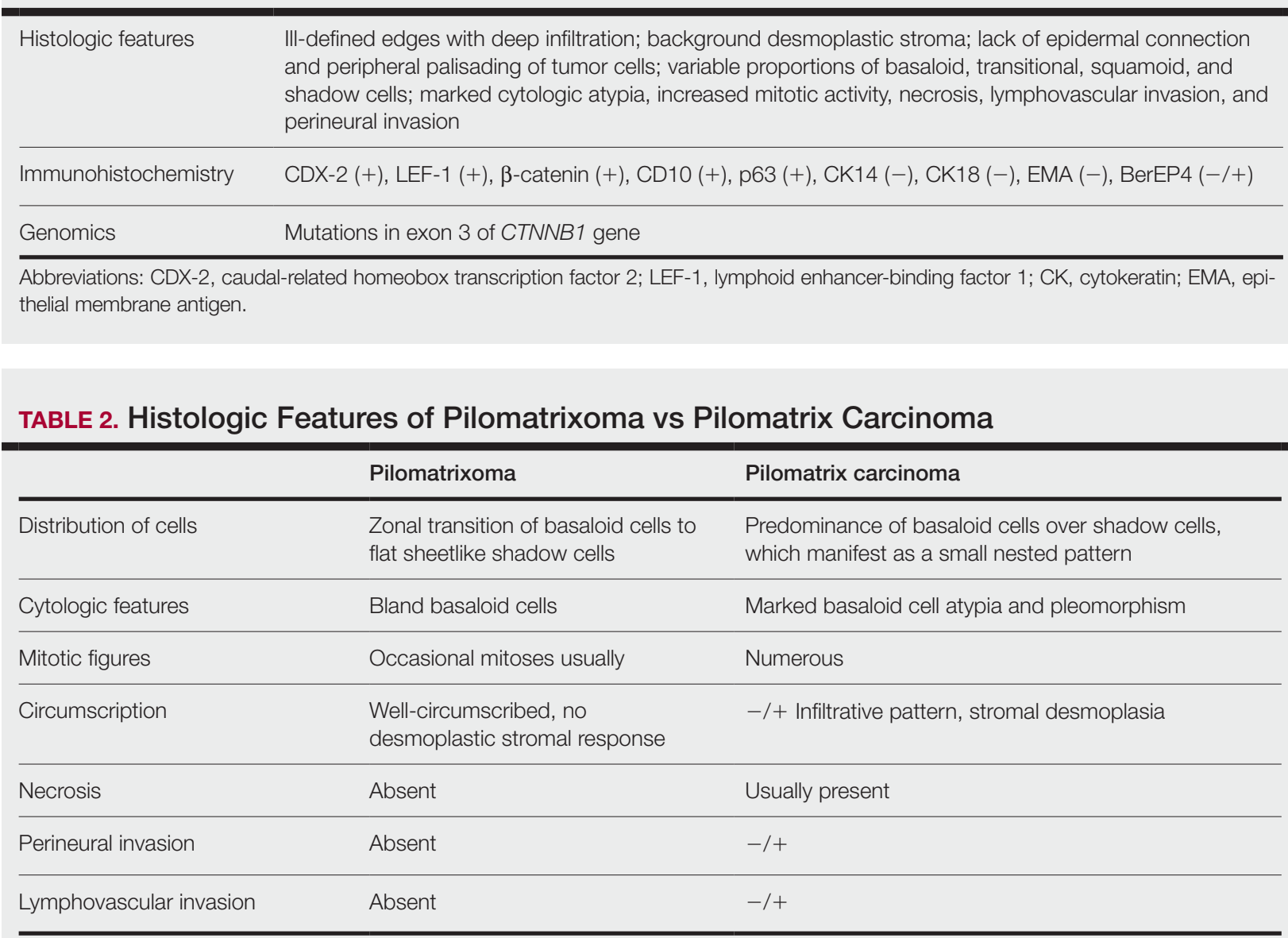

TABLE 3. Suggested Immunohistochemistry Panel in the Differential Diagnosis

\begin{tabular}{lllll}
\hline Immunohistochemistry & $\begin{array}{l}\text { Pilomatrix } \\
\text { carcinoma }\end{array}$ & $\begin{array}{l}\text { Squamous cell } \\
\text { carcinoma }\end{array}$ & $\begin{array}{l}\text { Sebaceous } \\
\text { carcinoma }\end{array}$ & $\begin{array}{l}\text { Basal cell } \\
\text { carcinoma }\end{array}$ \\
\hline EMA & - & + & + & - \\
\hline BerEP4 & $-1+$ & - & + & + \\
\hline Androgen receptor & $-/+$ & $-/+$ & + & $+/-$ \\
\hline
\end{tabular}

Abbreviation: EMA, epithelial membrane antigen.

unexpected, as melanocytes normally are present within the hair follicle matrix.

Pilomatrix carcinomas are aggressive tumors with a high risk for local recurrence and tendency for metastasis. In a study of 13 cases of pilomatrix carcinomas, Herrmann et $\mathrm{al}^{13}$ found that metastasis was significantly associated with local tumor recurrence $(P<.0413)$. They concluded that the combination of overall high local recurrence and metastatic rates of pilomatrix carcinoma as well as documented tumor-related deaths would warrant continued patient follow-up, especially for recurrent tumors. ${ }^{13}$ Rapid growth of a tumor, either de novo or following several months of stable size, should alert physicians to perform a diagnostic biopsy.

Management options of pilomatrix carcinoma include surgery or radiation with close follow-up. The most widely reported treatment of pilomatrix carcinoma is wide local excision with histologically confirmed clear margins. Mohs micrographic surgery is an excellent treatment option., ${ }^{2,13-15}$ Adjuvant radiation therapy may be necessary following excision. Currently there is no consensus on surgical management, and standard excisional margins 
have not been defined. ${ }^{26}$ Jones et $\mathrm{al}^{2}$ concluded that complete excision with wide margins likely is curative, with decreased rates of recurrence, and better awareness of this carcinoma would lead to appropriate treatment while avoiding unnecessary diagnostic tests. ${ }^{2}$

\section{Conclusion}

We report an exceptionally unique case of early pilomatrix carcinoma with a discussion on the pathogenesis and molecular pathology of hair matrix tumors. A large cohort of patients with longer follow-up periods and better molecular characterization is essential in drawing accurate information about their prognosis, identifying molecular markers that can be used as therapeutic targets, and determining ideal management strategy.

\section{REFERENCES}

1. Jani P, Chetty R, Ghazarian DM. An unusual composite pilomatrix carcinoma with intralesional melanocytes: differential diagnosis, immunohistochemical evaluation, and review of the literature. Am J Dermatopathol. 2008;30:174-177.

2. Jones $\mathrm{C}$, Twoon M, Ho W, et al. Pilomatrix carcinoma: 12-year experience and review of the literature. J Cutan Pathol. 2018;45:33-38.

3. Forbis R, Helwig EB. Pilomatrixoma (calcifying epithelioma). Arch Dermatol. 1961;83:606.

4. Elder D, Elenitsas R, Ragsdale BD. Tumors of epidermal appendages. In: Elder D, Elenitsas R, Jaworsky C, eds. Lever's Histopathology of the Skin 8th ed. Lippincott Raven; 1997:757-759.

5. Aherne NJ, Fitzpatrick DA, Gibbons D, et al. Pilomatrix carcinoma presenting as an extra axial mass: clinicopathological features. Diagn Pathol. 2008;3:47.

6. Papadakis $\mathrm{M}$, de Bree E, Floros $\mathrm{N}$, et al. Pilomatrix carcinoma: more malignant biological behavior than was considered in the past. Mol Clin Oncol. 2017;6:415-418.

7. LeBoit PE, Parslow TG, Choy SH. Hair matrix differentiation: occurrence in lesions other than pilomatricoma. Am J Dermatopathol. 1987;9:399-405.

8. Campoy F, Stiefel P, Stiefel E, et al. Pilomatrix carcinoma: role played by MR imaging. Neuroradiology. 1989;31:196-198.

9. Tateyama H, Eimoto T, Tada T, et al. Malignant pilomatricoma: an immunohistochemical study with antihair keratin antibody. Cancer. 1992;69:127-132.
10. O'Donovan DG, Freemont AJ, Adams JE, et al. Malignant pilomatrixoma with bone metastasis. Histopathology. 1993;23:385-386.

11. Cross P, Richmond I, Wells S, et al. Malignant pilomatrixoma with bone metastasis. Histopathology. 1994;24:499-500.

12. Niedermeyer HP, Peris K, Höfler H. Pilomatrix carcinoma with multiple visceral metastases: report of a case. Cancer. 1996;77:1311-1314.

13. Herrmann JL, Allan A, Trapp KM, et al. Pilomatrix carcinoma: 13 new cases and review of the literature with emphasis on predictors of metastasis. J Am Acad Dermatol. 2014;71:38-43.

14. Xing L, Marzolf SA, Vandergriff $\mathrm{T}$, et al. Facial pilomatrix carcinomas treated with Mohs micrographic surgery. JAAD Case Rep. 2018;4:253-255.

15. Fernandez-Flores A, Cassarino DS. Sarcomatoid pilomatrix carcinoma. J Cutan Pathol. 2018;45:508-514.

16. Sau P, Lupton GP, Graham JH. Pilomatrix carcinoma. Cancer. 1993;71:2491-2498.

17. Chan E, Gat U, McNiff JM, et al. A common human skin tumour is caused by activating mutations in $\beta$-catenin. Nat Genet. 1999;21:410-413.

18. Huelsken J, Vogel R, Erdmann B, et al. $\beta$-catenin controls hair follicle morphogenesis and stem cell differentiation in the skin. Cell. 2001;105:533-545.

19. Kikuchi A. Tumor formation by genetic mutations in the components of the Wnt signaling pathway. Cancer Sci. 2003;94:225-229.

20. Durand M, Moles J. Beta-catenin mutations in a common skin cancer: pilomatricoma. Bull Cancer. 1999;86:725-726.

21. Lazar AJF, Calonje E, Grayson W, et al. Pilomatrix carcinomas contain mutations in CTNNB1, the gene encoding beta-catenin. J Cutan Pathol. 2005;32:148-157.

22. Kazakov DV, Sima R, Vanecek T, et al. Mutations in exon 3 of the CTNNB1 gene ( $\beta$-catenin gene) in cutaneous adnexal tumors. Am J Dermatopathol. 2009;31:248-255.

23. Tumminello K, Hosler GA. CDX2 and LEF-1 expression in pilomatrical tumors and their utility in the diagnosis of pilomatrical carcinoma. $J$ Cutan Pathol. 2018;45:318-324.

24. Rodić N, Taube JM, Manson P, et al Locally invasive dermal squamomelanocytic tumor with matrical differentiation: a peculiar case with review of the literature. Am J Dermatopathol. 2013;35:E72-E76.

25. Perez C, Debbaneh M, Cassarino D. Preference for the term pilomatrical carcinoma with melanocytic hyperplasia: letter to the editor. J Cutan Pathol. 2017;44:655-657.

26. Herrmann JL, Allan A, Trapp KM, et al. Pilomatrix carcinoma: 13 new cases and review of the literature with emphasis on predictors of metastasis. J Am Acad Dermatol. 2014;71:38-43. 